\title{
FILOSOFIA, ANARQUISMO E DIREITOS HUMANOS: POR UMA ABORDAGEM LIBERTÁRIA
}

\author{
Filosohy, anarquism and human rights: for a libertarian approach \\ Filosofía, anarquismo y derechos humanos: por un enfoque libertario
}

RESUMo Este artigo tem o objetivo de apresentar uma reflexão sobre a temática dos Direitos Humanos colocando em contraponto a leitura de Waldemar Valle Martins (1978) com um texto de Mikhail Bakunin (2011), partindo de uma perspectiva interdisciplinar entre Filosofia e História. As discussões seguem a lógica de análise proposta por Martins quando o autor, buscando fundamentar filosoficamente os Direitos Humanos, exibe diferentes concepções a respeito do que é o ser humano e como essas concepções podem moldar a forma de encarar os direitos fundamentais para todos os homens e mulheres. Também será demonstrado o quão conflituoso era o contexto histórico que envolveu as discussões na Assembleia da ONU no momento em que a Declaração Universal dos Direitos Humanos (1948) fora aprovada por delegados de diversos países, abordando a abstenção dos países do antigo bloco soviético, como demonstram fontes da época produzidas pela imprensa. As contribuições de Bakunin são referenciadas ao longo de todo o texto, visando demonstrar o potencial do pensamento anarquista na construção de uma sociedade livre de injustiça e desigualdade social, tal qual muitos dos defensores dos Direitos Humanos poderiam sonhar, e para além do sonho, efetivamente lutar.

PalaVras-chave: Filosofia. História. ANARQuismo. Direitos HuMANOS.

ABSTRACT This article aims to present a reflection on the theme of Human Rights, putting in counterpoint the reading of Waldemar Valle Martins (1978) with a text by Mikhail Bakunin (2011), starting from an interdisciplinary perspective between Philosophy and History. The discussions follow the logic of analysis proposed by Martins when the author, seeking to substantiate the human rights philosophically, presents different conceptions about what the Human Being is and how these conceptions can shape the way of considering the rights fundamental for all men and women. It will also be shown how conflicting was the historical context surrounding the discussions in the UN General Assembly at the time when the Universal Declaration of Human Rights (1948) was adopted by delegates from various countries, addressing the abstention of the countries of the former Soviet bloc as ac-

\section{Douglas Pinheiro Graciano Instituto Federal de São Paulo- IFSP}

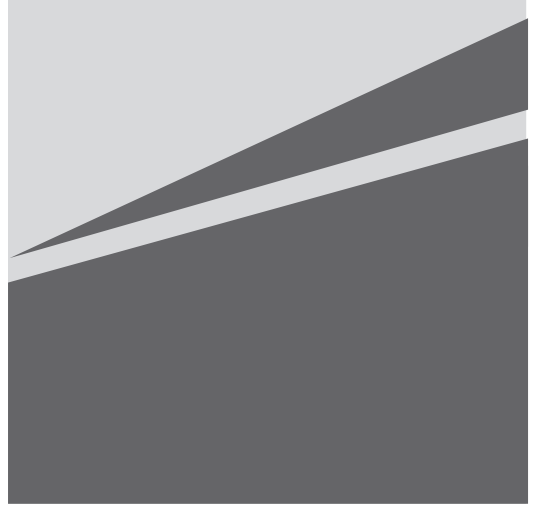


cording to press sources. Bakunin's contributions are referred throughout the text to demonstrate the potential of anarchist thinking in the construction of a society free from injustice and social inequality, as many human rights defenders could dream, and beyond the dream, effectively fight.

KEYWORDS: PHILOSOPHY. HISTORY. ANARCHISM. HUMAN RIGHTS.

RESUMEN Este artículo tiene el objetivo de presentar una reflexión sobre la temática de los Derechos Humanos colocando en contrapunto la lectura de Waldemar Valle Martins (1978) con un texto de Mikhail Bakunin (2011), partiendo de una perspectiva interdisciplinaria entre Filosofía e Historia. Las discusiones siguen la lógica de análisis propuesta por Martins cuando el autor, buscando fundamentar filosóficamente los Derechos Humanos, exhibe diferentes concepciones acerca de lo que es el ser humano y cómo esas concepciones pueden moldear la forma de encarar los derechos fundamentales para todos los hombres y mujeres. También se demostrará cuán conflictivo era el contexto histórico que involucró las discusiones en la Asamblea de la ONU en el momento en que la Declaración Universal de los Derechos Humanos (1948) había sido aprobada por delegados de diversos países, abordando la abstención de los países del antiguo bloque soviético, demuestran fuentes de la época producidas por la prensa. Las contribuciones de Bakunin son referenciadas a lo largo de todo el texto, buscando demostrar el potencial del pensamiento anarquista en la construcción de una sociedad libre de injusticia y desigualdad social, tal cual muchos de los defensores de los Derechos Humanos podrían soñar, y más allá del sueño, efectivamente luchar.

palabras clave: Filosofía. historia. Anarquismo. Derechos HUMANOS.

\section{INTRODUÇ̃̃o}

E m 1948, o mundo ainda amargurava o desastre da Segunda Guerra Mundial. Nesse mesmo ano a Organização das Nações Unidas apresentou a Declaração Universal dos Direitos Humanos, fruto de um intenso debate com a participação de delegados representantes dos países ao redor do globo. De acordo com a própria Declaração, havia naquele momento a preocupação em resguardar as pessoas contra "a tirania e a opressão" e legitimar uma luta em defesa da dignidade humana, independente de gênero, raça ou nacionalidade.
No ano de 1978, foi publicado o livro Direitos Humanos, pela Editora Paulinas. Essa obra faz parte da coleção Teologia em diálogo, e em vários de seus artigos há discussões sobre os direitos humanos sob a perspectiva do pensamento cristão. Dentro desse livro há um artigo intitulado "Direitos Humanos: Aspectos Filosóficos", escrito por Waldemar Valle Martins (1926-2004), que exerceu durante sua vida a função de padre e professor de filosofia, tendo atuado em diferentes instituições de ensino superior no Brasil.

Fazendo contraponto à leitura de Martins, apresentarei alguns fundamentos do pensamento anarquista de Mikhail Baku- 
nin (1814-1876), expressos na obra Deus e o Estado, ${ }^{1}$ visando demonstrar o potencial dessa filosofia para uma conceptualização sobre o que é ser humano e quais as possibilidades de transformação da sociedade, dentro de uma linha de pensamento libertária, entendendo que Liberdade e Igualdade são aspectos necessários para a formação de um ambiente social que estimule a vivência e o crescimento dos indivíduos de acordo com as suas potencialidades.

Infelizmente, o debate acadêmico desconhece muitas das teses, tendências, e autores representantes da filosofia anarquista, devido às perseguições políticas contra essa corrente de pensamento, jogado tantas vezes na clandestinidade ou interpretado como movimento de baderneiros. Eric Hobsbawm (1995) teceu comentários sobre a inserção da teoria anarquista nos movimentos sociais de trabalhadores, demonstrando que essa corrente já foi mais proeminente que o próprio marxismo, pelo menos até a segunda metade do século XX. De acordo com o historiador:

Antes de 1914, o anarquismo fora muito mais uma ideologia impulsora de ativistas revolucionários que o marxismo em grande parte do mundo. (...) Na década de 1930 o anarquismo deixara de existir como força política importante fora da Espanha, mesmo na América Latina, onde a bandeira vermelha e preta tradicionalmente inspirara mais que a vermelha. (Mesmo na Espanha a Guerra Civil ia destruir o anarquismo, enquanto fazia a fortuna dos comunistas, até então relativamente insignificantes) (HOBSBAWM, 1995, p. 80).

Consta na apresentação do livro: "Escrito em 1871, Deus e o Estado é um texto filosófico, fundamental para a compreensão do pensamento bakuniniano, que condensa a maior parte dos principais temas debatidos pelo autor em sua fase anarquista: o método dialético, o evolucionismo e o naturalismo, o papel da ciência, os conceitos de liberdade e de livrearbítrio e o materialismo" (2011).
Algumas décadas antes da Revolução Russa (1917), Bakunin já antecipava a tese de que uma revolução que se amparasse em um Estado como condutor do processo estaria fadada ao fracasso, visto que a própria oposição entre governantes e governados significaria um atentado ao princípio de igualdade. Mesmo que o partido político no poder fosse constituído apenas de proletários ou intelectuais "revolucionários", as disputas pelo poder e as tendências autoritárias inerentes aos homens de Estado levariam à criação de novas condições para que o capitalismo se reproduzisse, reproduzindo por consequência a desigualdade e ausência de liberdade.

De olho na atualidade, em tempos de crise das instituições políticas, do sistema representativo e de recrudescimento de discursos fascistas nocivos à coletividade, a filosofia anarquista propõe reflexões que podem contribuir na interpretação da sociedade, voltada para a transformação social e para melhor atender às necessidades da população, especialmente daqueles que vivem em situações de vulnerabilidade social.

\section{Filosofia E direitos humanos}

O artigo "Direitos Humanos: Aspectos Filosóficos", de Waldemar Valle Martins, apresenta uma reflexão em torno do debate filosófico sobre o sentido dos Direitos Humanos, perpetrados pela Declaração de 1948. Passados quarenta anos, desde sua publicação, o livro contém reflexões bastante atuais, afinal o debate a respeito dos direitos fundamentais de todos os homens e mulheres se encontra em verdadeira nebulosidade, sem mencionar a vagarosidade com a qual os diversos Estados ao redor do mundo se mantiveram na tarefa de garantir os direitos de seus cidadãos. Essa situação nos impõe o ato de questionar a realidade.

O autor conceitua a respeito do sentido da Filosofia, argumentando que o discurso filosófico é "uma instância crítica, uma busca de racionalidade, uma reflexão que é o debruçar-se sobre a realidade para desvelar 
a sua estrutura, o seu modo de ser, a sua gênese e o seu desenvolvimento, a sua razão última" (MARTINS, 1978, p. 73). Segundo consta no artigo, a filosofia não deve estar alheia à realidade, "sob a pena de proferir um discurso vazio" (p. 73), muito pelo contrário, "do real deve colher a matéria-prima para a elaboração de seu texto subsidiado pelas Ciências" (p. 73). Aos pensadores cabe a tarefa de questionar racionalmente a realidade, contrapondo a aridez das sociedades "tecnocratas" com o campo fértil do pensamento filosófico.

Seguindo o raciocínio de Martins, a Filosofia pode contribuir na discussão sobre os Direitos Humanos, buscando uma fundamentação que sirva como base para a sua defesa. Quanto a essa problemática, Martins afirma a relevância de compreender as maneiras diferentes de conceber o homem, colocando em vista a existência de diversas correntes de pensamento. Cada corrente aponta para aspectos diversos acerca da essência humana, decorrendo disso algumas divergências na interpretação daquilo que objetivamente deve ser considerado como Direito Fundamental de cada pessoa existente na face da Terra. Em resumo, faz muita diferença entender as concepções de homem, pois pontos de vista diferentes a respeito do que é ser humano podem resultar em concepções diversas acerca do que deve ser considerado indispensável na constituição dos Direitos Humanos.

\section{O QUE É SER HUMANO?}

Surgem os questionamentos: o que é o humano de acordo com a filosofia? Em meio a variadas correntes, o autor identifica duas maneiras gerais de se conceber o Homem. De um lado, temos as correntes que concebem os humanos como portadores de uma natureza fixa e imutável, de outro, vemos as correntes filosóficas que vão entender que o Homem tem natureza social, essencialmente mutável.
As linhas de pensamento que interpretam o humano, principalmente sob o aspecto determinado pela natureza são, por exemplo, as representantes do pensamento cristão, pois admitem que o homem "é criatura de Deus, possuindo, pois, uma natureza ou essência que o coloca em determinado nível na escala dos seres criados" (MARTINS, p. 74). Waldemar Martins ainda pontua a influência do pensamento grego na formulação das hipóteses de concepção cristã, sendo que o primeiro ofereceu "categorias de natureza" e "essência" para elevar a crença cristã no milagre da criação ao nível racional.

Como representante das correntes que interpretam o humano pelo prisma do social, o autor cita as hipóteses formuladas pelo marxismo, como a afirmação de que "Tudo o que uma pessoa faz é essencialmente social” ( $p$. 75). Martins afirma que, de acordo com o pensamento marxista, a diferença essencial entre o humano e os outros animais é a capacidade de produzir os próprios meios de subsistência, sendo que o trabalho possui cunho social, visto que envolve várias pessoas na execução das tarefas.

Apenas tomando esses dois prismas cristão e marxista - é possível entrever as dificuldades de se fundamentar direitos para humanos concebidos de formas tão diferentes. A citação a seguir sugere o diagnóstico:

(...) as divergências aprofundam-se, se observarmos que, para o cristão, o homem - na ordem da graça - é filho de Deus, com uma destinação que o encaminha a participar definitivamente da família divina; enquanto no marxismo, o materialismo histórico dialético elimina a ideia de Deus, de sobrevivência após essa vida e detém-se na tarefa de construir, aqui, neste mundo, uma sociedade sem classes, alcançada pela superação do atual sistema econômico e com a socialização dos meios de produção (MARTINS, p. 75). 


\section{O SER HUMANO SOB A PERSPECTIVA DE Mikhail BakUnin}

Ainda no século XIX, o pensador e revolucionário Mikhail Bakunin formulou uma concepção que considerava o humano portador de uma natureza tanto "fixa" quanto "social". "Fixa" no sentido de que tinha características básicas determinadas pela própria natureza, ao mesmo tempo em que possuía uma "natureza social", considerando a cooperação entre os indivíduos como fator privilegiado na formação da sociedade. Bakunin estava sob o alcance da teoria da evolução e por isso entendia que a humanidade passaria por fases de desenvolvimento, até que alcançasse uma sociedade que conciliasse igualdade social e material com liberdade de viver de acordo com as próprias potencialidades.

Bakunin vai identificar três elementos ou princípios básicos que constituem, "na história, as condições básicas de todo desenvolvimento humano, coletivo ou individual" (BAKUNIN, 2011, p. 37). Esses três elementos são: " $1{ }^{\circ}$., a animalidade humana; $2^{\circ}$., o pensamento; $3^{\circ}$., a revolta. À primeira corresponde propriamente a economia social e privada; à segunda, a ciência; à terceira, a liberdade" (p. 37). O anarquista afirma que "o mundo social, o mundo propriamente humano, a humanidade numa palavra, outra coisa não é senão o desenvolvimento supremo, a manifestação mais elevada da animalidade" (BAKUNIN, p. 38).

Bakunin expõe uma concepção de homem muito coerente com a realidade, apesar das próprias limitações históricas que reconhecemos em sua obra, limitações que não impedem a apreensão de princípios importantes para a formação de uma sociedade mais justa. Nas palavras dele:

O homem, como toda natureza viva, é um ser completamente material. O espírito, a faculdade de pensar, de receber e de refletir as diferentes sensações exteriores e interiores, de lembrar-se delas quando passaram, e de reproduzi- -las pela imaginação, compará-las e distingui-las, abstrair as determinações comuns e criar assim noções gerais (...) numa palavra, a inteligência, única criadora de todo o nosso mundo ideal, é uma propriedade do corpo animal e, especialmente, do organismo cerebral (p. 103).

\section{EM bUSCA DE UM CONSENSO...}

Retomando o artigo de Waldemar Valle Martins, em seu exame sobre as diferentes correntes de pensamento a respeito do homem, o autor chega a entrever um possível consenso entre as filosofias, trazendo um exemplo do campo da psicologia: Burrhus Skinner versus Sigmund Freud. Martins demonstra que Skinner dedicava mais ênfase aos aspectos sociais (fatores ambientais) como determinantes do comportamento humano, enquanto Freud privilegiava os aspectos individuais (estados inconscientes) como determinantes da consciência.

De acordo com as palavras de Martins: "Skinner, no campo da psicologia, valoriza o condicionamento e explica que o comportamento do homem é determinado por leis, que impõem conexões causais entre os fatores ambientais e o seu agir" (p. 75). Sobre o pai da psicanálise é citado: "Para Freud, a consciência não é perfeitamente livre e racional, mas determinada por estados mentais inconscientes" (MARTINS, 1978, p. 75).

Se forem consultados outros campos de conhecimento, será possível notar outras concepções de humano que focalizam a influência de uma natureza humana supostamente mais "fixa" ou mais "social", como cita Martins: "Essa alternativa de inato ou social manifesta-se nos binômios biológico-cultural; hereditário-ambiental; espontâneo-educado; instintivo-condicionado (...)" (p. 75). São inúmeras as combinações possíveis, e isso nos faz perceber que existem vários fatores que determinam o modo de agir das pessoas. $\mathrm{O}$ autor conclui: 
Poderíamos afirmar, sem temeridade e sem simplificar perigosamente, que as várias teorias não são totalmente incompatíveis em todas as suas propostas, mas; sob diversos ângulos, elas sublinham aspectos relevantes da verdade total sobre o homem (MARTINS, 1978, p. 75).

O filósofo parece ter alcançado a "verdade total do homem" por meio de um consenso parcial entre a heterogeneidade de pensamento, porém excluindo as interpretações religiosas sobre a humanidade. $\mathrm{O}$ autor pontua um aspecto muito relevante quando argumenta que a compatibilização entre as diversas correntes filosóficas só seria possível se desconsiderássemos "as afirmações de ordem metafísica (existência de Deus, sobrevivência do homem) e do plano da revelação (filiação divina), que não se compaginam com o materialismo" (p. 75).

Nisso, retomo Bakunin por ele ter formulado toda uma teoria contrária à metafísica e ao que ele chamou de "idealismo", em contraposição à posição "materialista" que assumia. O filósofo russo criticou severamente o pensamento metafísico e idealista partindo do raciocínio de que, ao formularem hipóteses de um mundo sobrenatural, supostamente livre de imperfeições, esses pensadores acabaram desvalorizando a matéria viva de que somos constituídos, resultando igualmente na desvalorização do humano em sua plenitude. Como o anarquista russo afirmou:

(...) o céu religioso nada mais é do que uma miragem onde o homem, exaltado pela ignorância e pela fé, encontra sua própria imagem, mas ampliada e invertida, isto é, divinizada. (...) o Céu enriqueceu-se com os despojos da Terra, e, por consequência necessária, quanto mais o Céu se tornava rico, mais a humanidade e a Terra tornavam-se miseráveis (BAKUNIN, 2011, p. 54).
Considerando apenas o debate a respeito da existência de uma divindade, ou sobre qual seria o segmento religioso portador da Verdade, esses já seriam suficientes para gerar inúmeros desentendimentos e dissensos. Em proporção maior, basta considerarmos as constantes guerras e perseguições religiosas pelo mundo afora, ou em nossa própria terra. Por sua vez, a tentativa de se entrever uma compatibilidade entre as diferentes teorias não deve excluir o reconhecimento das disputas e conflitos entre as correntes (filosóficas, religiosas ou políticas), sob a pena de fechar "os olhos à realidade", como bem definiu Martins (1978).

\section{DeclaraÇão CONFlituosa: O CASO DA URSS}

A Declaração dos Direitos do Homem e do Cidadão, de 1948, esteve permeada de conflitos. Sabe-se que esse documento fez parte de uma iniciativa da Organização das Nações Unidas, numa tentativa de compensar todas as perdas humanas resultantes das duas guerras mundiais e das perseguições étnicas. Eric Hobsbawm comenta sobre a ONU de forma bastante pessimista, questionando a capacidade de ação desse órgão:

O melhor que se pode dizer dessa organização é que, ao contrário de sua antecessora, a Liga das Nações, a ONU continuou existindo por toda a segunda metade do século XX e na verdade se tornou um clube cuja filiação, cada vez mais, mostrava que um Estado fora formalmente aceito como soberano internacionalmente. Não tinha, pela natureza de sua constituição, poderes nem recursos independentes dos que lhe eram destinados pelas nações membros e, portanto, não tinha poderes de ação independente (HOBSBAWM, 1995, p. 419). 
Assim o historiador percebe que as limitações da ONU foram impostas pelos diversos poderes que a mantinham, no caso, as lideranças dos Estados considerados "soberanos", e em especial as potências mundiais. Esse pessimismo ainda se explica pela própria trajetória do breve século XX que mesmo após o morticínio generalizado da Segunda Guerra Mundial, que vitimou cerca de 60 milhões de pessoas, ainda experimentou outros conflitos armados, de guerras civis a invasões militares imperialistas nos países de terceiro mundo.

Walter Benjamin (1892-1940) afirmou em suas teses sobre a filosofia da história que "Não há um documento da cultura que não seja ao mesmo tempo um documento da barbárie" (BENJAMIN, 1985, p. 157). Guardada as devidas proporções, essa frase pode ajudar a desvelar um significado por trás da Declaração Universal dos Direitos Humanos: o documento representa uma das maiores conquistas da sociedade contemporânea em termos humanitários e ao mesmo tempo contém, em cada um de seus parágrafos, milhões de histórias de vidas devastadas pela guerra, pelo genocídio e pela opressão.

Entre Benjamin e Bakunin, pode-se arriscar uma confluência de ideias, pois ambos os filósofos apresentam uma sensibilidade aos sofredores e oprimidos, incitando a tomada de posições ao lado da classe trabalhadora, criticando o proceder da ciência histórica daqueles historiadores ditos imparciais, metódicos, positivistas e/ou historicistas, já que para Benjamin esse tipo se identificava claramente com os "vencedores".

Segue-se uma citação de Bakunin sobre a limitação da ciência histórica, que naquele momento em que escrevera, só poderia conter "apreciações gerais e, por consequência, abstratas” (BAKUNIN, 2011, p. 99). Prosseguindo a citação:

Os bilhões de indivíduos que forneceram a matéria viva e sofredora dessa história, ao mesmo tempo triunfante e lúgubre - triunfante pela imensa hecatombe de vítimas "esmagadas sob sua carruagem" -, esses bilhões de obscuros indivíduos, sem os quais nenhum dos grandes resultados abstratos da história teria sido obtido - e que, notemo-lo bem, jamais se beneficiariam com qualquer desses resultados -, não encontrarão sequer o mínimo lugar em nossos anais. Eles viveram e foram sacrificados pelo bem da humanidade abstrata; eis tudo! (BAKUNIN, 2011, p. 99).

Walter Benjamin fez uma crítica enfática ao historicismo: um tipo de História que se autoproclamava objetiva por considerar como fontes históricas majoritariamente os documentos escritos oficiais. Um tipo de História que, para o autor, "pretende apresentar a imagem "eterna" do passado" e "não tem armação teórica. Procede por adição: conclama a massa dos fatos para preencher o tempo vazio e homogêneo" (BENJAMIN, 1985, p. 162). Para Benjamin:

(...) afinal, com quem se identifica o historiador do historicismo? A inelutável resposta é: com o vencedor. Os dominadores num certo momento histórico são, no entanto, os herdeiros de todos aqueles que alguma vez já venceram. (...) Quem até esta data sempre obteve a vitória participa da grande marcha triunfal que o dominador de hoje celebra por cima daqueles que hoje estão atirados no chão. Como era de costume, a pilhagem é arrastada junto no cortejo triunfal. Costuma-se chama-la bens culturais. No materialista histórico, eles terão de contar com um observador distanciado. Pois tudo o que ele consegue perceber em termos de bens culturais, tudo, sem exceção, tem uma origem que ele não pode rememorar sem horror (BENJAMIN, 1985, p. 156-157). 
Ao considerarmos esses dois textos, percebemos uma identificação com a multidão sofredora ao longo da história. Outras aproximações do pensamento benjaminiano com o anarquismo já foram abordadas por Otte e Volpe (2000) que, segundo os autores, a autoafirmação de Walter Benjamin como materialista histórico estava longe de um posicionamento ortodoxo na corrente marxista. Como consta no artigo, sobre a perspectiva revolucionária na obra de Benjamin:

Não os chavões dos tiros e da explosão, mas a apologia do "agora" revela uma certa proximidade não confessa - de Benjamin com o anarquismo. (...) O anarquismo de cunho benjaminiano se revela como bastante realista, pois luta pela libertação daquilo que efetivamente aconteceu. Ao invés de sacrificar o passado em favor da utopia - se é que se pode sacrificar algo considerado morto - o anarquista abriria o acesso ao "passado oprimido" e permitiria olhar para trás. Nas "Teses", o olhar utópico para fora da história é substituído pela ação 'intra-histórica', o projeto para o futuro pelo "choque" no presente. $\mathrm{O}$ "choque" enquanto elemento do método anarquista não se restringiria à ação política, mas faria parte da 'epistemologia' benjaminiana (OTTE e VOLPE, 2000, p. 43).

Walter Benjamin teve um triste destino por conta da perseguição nazista sofrida tanto pela sua ascendência judaica, quanto pelo posicionamento político, juntando-se à multidão daqueles que tombaram no lado dos vencidos. As "Teses sobre a Filosofia da História” constitui o último escrito produzido pelo autor antes de sua morte trágica. Sua obra é relevante tanto pela contribuição epistemológica à construção do conhecimento histórico, quanto pelo seu caráter de fonte documental, representando as palavras de um batalhador pela causa dos oprimidos, em seu derradeiro "instante de perigo".

Tratando-se sobre o sentido histórico da Declaração de 1948, o autor Fábio Comparato (2012) vai dizer que o preâmbulo desse documento expõe "o impacto das atrocidades cometidas durante a $2^{\text {a }}$ Guerra Mundial" (p. 223), atrocidades cometidas não só pelos países do Eixo, mas também pela União Soviética e pelas potências ocidentais, temporariamente anulados ou ignorados. "Além disso, nem todos os membros das Nações Unidas, à época, partilhavam por inteiro as convicções expressas no documento: embora aprovado por unanimidade, os países comunistas (...), a Arábia Saudita e a África do Sul abstiveram-se de votar" (p. 223). O autor conclui:

Seja como for, a Declaração, retomando os ideais da Revolução Francesa, representou a manifestação histórica de que se formara, enfim, em âmbito universal, o reconhecimento dos valores supremos da igualdade, da liberdade e da fraternidade entre os homens, como ficou consignado em seu artigo I (COMPARATO, 2012, p. 223).

Um documento com alto grau de importância, que representa um avanço da civilização humana, contém por trás dele toda a barbárie, como Benjamin nos permitiu ver em sua análise dos "bens culturais". Retomando a contribuição de Comparato nessa discussão:

Esse reconhecimento universal da igualdade humana só foi possível quando, ao término da mais desumanizadora guerra de toda a História, percebeu-se que a ideia de superioridade de uma raça, de uma classe social, de uma cultura ou de uma religião, sobre todas as demais, põe em risco a própria sobrevivência da humanidade (COMPARATO, 2012, p. 225). 
Sobre a atuação do antigo bloco socialista, Comparato já deixou claro que a União Soviética, junto de seus países satélites, ofereceu certa resistência quanto a alguns pontos da Declaração da ONU. Uma matéria publicada pelo Jornal do Brasil, ${ }^{2}$ em 11 de dezembro de 1948, vai enfatizar a atuação do "bloco eslavo" no conselho das Nações Unidas:

A assembleia Geral das Nações Unidas aprovou a Declaração dos Direitos Humanos

A última hora a Rússia tentou adiar a votação ou emendar o projeto, mas sua iniciativa foi derrotada Abstiveram-se de votar os países do bloco eslavo (JORNAL DO BRASIL, 1948, p. 7). ${ }^{3}$

A notícia relata o debate protagonizado pelo delegado soviético Andrey Vyshinsky durante as votações dos artigos da Declaração Universal dos Direitos Humanos. De acordo com a matéria de jornal analisada, o delegado soviético criticou diversos artigos que considerava vagos e abstratos, por exemplo, artigo referente à liberdade de opinião, alegando que poderia significar uma brecha para a propagação de discursos fascistas e belicistas. Como relata a própria notícia: "Referiu-se em particular ao artigo sobre o direito à liberdade de opinião e disse que o seu país jamais permitiu que se desse completa liberdade de expressão às ideias fascistas e às ideias belicistas" (JORNAL DO BRASIL, 1948, p. 7).

A posição de Vyshinsky aparentemente valoriza a preservação da coletividade contra discursos desagregadores, em detrimento do direito individual de liberdade de expressão. Não é estranho pensar que muitos grupos de extrema direita da atualidade, no Brasil e no

2 Disponível on-line na Hemeroteca Digital da Biblioteca Nacional do Rio de Janeiro.

3 "A assembleia Geral das Nações Unidas aprovou a Declaração dos Direitos Humanos": JORNAL DO BRASIL. Rio de Janeiro, 11 dez. 1948, p. 7-9. mundo, se amparam no direito de liberdade de expressão para justificar discursos de ódio de cunho machista, racista ou homofóbico. Por sua vez, pode-se interpretar as objeções de Vyschinsky à liberdade de opinião como o lado sombrio do regime stalinista, mentor de perseguições políticas e expurgos.

É necessário fazer a mediação entre coletivo-individual sobre uma perspectiva libertária. Uma das soluções quanto aos discursos fascistas, autoritaristas e de ódio exige trabaIho e dedicação, falo do papel da educação escolar, em especial aquela que assuma a tarefa emancipatória e libertária. Bakunin oferece um subsídio para engendrarmos formas de se educar para a emancipação:

Será necessário fundar toda a educação das crianças e sua instrução sobre o desenvolvimento científico da razão, não sobre a fé; sobre o desenvolvimento da dignidade e da independência pessoais, não sobre o da piedade e da obediência; sobre o culto da verdade e da justiça e, antes de tudo, sobre o respeito humano que deve substituir, em tudo e em todos os lugares, o culto divino (BAKUNIN, 2011, p. 74).

A ênfase no "respeito humano" é central para aqueles que buscam pensar uma Educação em Direitos Humanos, ou seja, uma ação pedagógica que educa visando o respeito, conscientizando os estudantes sobre a própria condição de indivíduos, incentivando a autonomia e, sobretudo, ensinando acerca da tolerância e da convivência pacífica com a variedade de modos de vida. Para Bakunin, "essa educação tem como objetivo final formar homens livres, cheios de respeito e de amor pela liberdade alheia" (p. 74). Eis um ótimo remédio contra a propagação de ideias fascistas e odiosas que, em longo prazo, é mais eficiente que qualquer tipo de censura estatal. 


\section{FundamentaÇão e Perspectivas QUANTO À DECLARAÇÃO UNIVERSAL DOS DIREITOS HUMANOS}

De volta ao texto de Waldemar V. Martins: buscando fundamentar filosoficamente os Direitos Humanos, o filósofo brasileiro compôs uma visão geral sobre o conjunto de direitos inseridos na Declaração da ONU ao longo dos seus trinta artigos. O autor destaca alguns eixos dentro do documento, que seriam os direitos individuais, civis, políticos e sociais. Nas palavras do autor:

$1^{\circ}$.) a defesa da vida individual e das condições de seu aperfeiçoamento (direitos individuais);

$2^{\circ}$.) a igualdade perante a lei com a tutela do indivíduo contra qualquer tratamento arbitrário (direitos civis);

$3^{\circ}$.) a relação entre governo e o consentimento dos governados, expressa, por exemplo, na existência de partidos políticos e em eleições livre e que defenda a participação do cidadão na escolha da forma de governo (direitos políticos);

$4^{\circ}$.) as condições de vida digna, afiançada por trabalho convenientemente remunerado (direitos sociais) (MARTINS, 1978, p. 80).

Martins vai argumentar no sentido de afirmar a legitimidade desses direitos, como aspectos possíveis e desejáveis na constituição da "cidade dos homens". Para além dos conflitos, existiria um cerne muito pertinente na declaração de 1948, sendo que os trinta artigos formalizados pela ONU serviriam então para resguardar a população em seus direitos individuais, civis, políticos e sociais, contra a opressão estatal e econômica, como disse o próprio autor: "reclamam-se os direitos contra o sistema que - qualquer que seja sua inspiração - tenda a absorver e estiolar as potencialidades do homem e a reduzi-lo a objeto" (MARTINS, 1978, p. 80).
Ademais, o professor Waldemar conclui que os Direitos Humanos devem ser apropriados pelo "direito positivo", de modo que as constituições e legislações dos Estados ao redor do mundo adotem leis que garantam os direitos fundamentais, contra as arbitrariedades do próprio Estado e a favor das garantias de condições materiais de existência, resguardando os modos de vida (cultura) de cada povo.

Infelizmente, poder político e econômico estão interligados. Sabemos quão nocivas são as leis formuladas por certos membros da classe dirigente que visam tão-somente aumentar a fortuna própria e de seus aliados que atuam pelo capital, passando por cima de tudo e de todos. Assim, de tempos em tempos, vemos o ataque contra os direitos trabaIhistas, contra as populações indígena e quilombola, contra as minorias sociais, varrendo para longe a emancipação do povo, jogando-o na pobreza material e espiritual. Em outras palavras, uma dolorosa e real violação dos Direitos Humanos perpetuada diariamente pelos donos do poder.

\section{OS DIREITOS HUMANOS E O ANARQUISMO BAKUNINIANO}

É possível articular alguns pontos de convergência ou discordância entre os artigos da Declaração dos Direitos Humanos com os princípios anarquistas de Bakunin. Cabe um adendo sobre o pensamento bakuniniano que, como todos os anarquistas, vai apontar que a desigualdade inerente à sociedade de classes só será superada por meio de uma revolução social, que dê fim, de uma só vez, do Estado, do capitalismo e da religião institucionalizada. Uma vez abolido o Estado, também seriam abolidas as formas de legislação, vistas como instrumentos da classe dominante para se manterem no poder.

Numa palavra, rejeitamos toda legislação, toda autoridade e toda influência privilegiada, titulada, oficial 
e legal, mesmo emanada do sufrágio universal, convencidos de que ela só poderia existir em proveito de uma minoria dominante e exploradora, contra os interesses da imensa maioria subjugada (BAKUNIN, 2011, p. 67).

As únicas leis que devemos conhecer e respeitar, segundo o anarquista russo, são as leis da natureza, afinal antes de tudo somos animais e fazemos parte de um ambiente naturalmente constituído. Esse aspecto do pensamento bakuninista faz todo o sentido nesse século $X X I$, pois vemos os impactos que o homem infringe na natureza. A industrialização e o crescimento econômico irrestrito estão gerando situações insustentáveis, e chegamos a pensar até que ponto a humanidade terá condições de existir neste planeta. A ótica anarquista foi sensível a esse desequilíbrio, sendo que Bakunin buscou fundar preceitos para uma sociedade que não se direcione unicamente para o lucro e a ganância de poucos, mas sim para a solidariedade, a autogestão da produção pelos trabalhadores, a cooperação e o respeito entre as pessoas e, mesmo que a preocupação de sua obra não gire em torno da questão ambiental, ela pode nortear posicionamentos que trilhem para a preservação dos recursos naturais e das populações tradicionais que mantêm ligações estreitas com a terra.

Tratando-se de "direitos individuais", Bakunin vai se posicionar contra as diversas formas de cercear a liberdade dos indivíduos, argumentando que o "respeito humano" deve ser o norteador das relações entre os diversos componentes da sociedade, levando a defesa da liberdade em suas nuanças mais contundentes. Quanto aos “direitos civis", Bakunin propunha não apenas a "igualdade perante a lei”, mas sim a inexistência de leis regidas pelos homens apoiados no Estado, pois elas sempre estariam a serviço de grupos do poder.

Quando o assunto é os "direitos políticos", o anarquismo reivindica a dissolução da divisão entre governantes e governados, defendendo a ideia de que as decisões que en- volvem a vida coletiva devem necessariamente ser tomadas pela coletividade, reunida em assembleias, sindicatos autogeridos e comunas, de maneira horizontal e igualitária. Por fim, os “direitos sociais", seguindo a lógica de Bakunin, não deveriam se resumir à condenação do trabalho escravo, substituindo-o pelo trabalho assalariado - afinal no sistema capitalista, o trabalhador mesmo que seja remunerado, ainda estará mantido em uma escravidão, como professa a tendência socialista libertária -, mas sim de atestar a autonomia dos trabalhadores no processo produtivo, sendo eles os próprios detentores dos meios de produção, voltada não mais para o lucro de alguns privilegiados, mas sim, para atender às necessidades de cada pessoa.

Para Bakunin (2011), em última instância, apenas a derrubada dos sistemas econômico e político será capaz de garantir uma vida digna e plena para os habitantes deste mundo. Não basta a queda do poder hierarquizado e a mudança de sistema econômico, mas sim reorganizar a sociedade para possibilitar a emergência de uma noção coletiva dos deveres humanos para atender às necessidades humanas. Como afirma Bakunin:

Fazei a revolução social. Fazei com que todas as necessidades tornem-se solidárias, que os interesses materiais e sociais de cada um tornem-se iguais aos deveres humanos de cada um. E, para isso, só há um meio: destruí todas as instituições da desigualdade; estabelecei a igualdade econômica e social de todos, e, sobre essa base, elevar-se-á a liberdade, a moralidade, a humanidade solidária de todos (BAKUNIN, 2011, p. 77).

Bakunin (2011) vai entender que Igualdade e Liberdade são pilares essenciais e interdependentes da nova sociedade a ser criada: com a queda do sistema de controle e dominação do povo, urdiria uma sociedade ancorada na completa igualdade social e material, sem que 
isso signifique padronização, pois na Anarquia todos poderiam viver uma vida de acordo com as suas potencialidades, livres de qualquer forma de impedimento ou constrangimento causados pela sociedade como hoje é.

A contribuição da corrente filosófica anarquista na ação de transformar a sociedade resultou em lutas sociais e reivindicações muito objetivas e verdadeiras, por exemplo, o evento que envolveu um grupo de operários anarquistas, os chamados "mártires de Chicago", que perderam suas vidas por uma condenação injusta, após participarem, ativamente, no ano de 1886 , de manifestações e paralisações em busca da redução da jornada de trabalho para oito horas diárias!` $\mathrm{O}$ anarquismo busca atuar no aqui e agora, criando o choque contra a (des)ordem estabelecida, extrapolando os limites de uma filosofia esvaziada de sentido real, ao despertar "a consciência de explodir com o continuum da história" (BENJAMIN, 1985, p. 161).

\section{CONSIDERAÇões FINAIS}

Mesmo que a Declaração Universal dos Direitos Humanos possa ser considerada insuficiente em alguns pontos, ela pode e deve ser transformada em plataforma de luta, em vista dos constantes casos de desrespeito à vida. Em um país em que militantes dos direitos humanos são assassinados(as), vemos a urgência dessa bandeira estampada no sofrimento

4 O feriado de $1^{\circ}$. de Maio é uma homenagem para estes bravos lutadores: Parsons, Spies, Fischer, Engel e Lingg. Mais informações: http://www.anarquista. net/os-martires-de-chicago/ ou WOODCOCK, George. História das idéias e movimentos anarquistas, v. 2: O movimento/George Woodcock; tradução de Júlia Tettamanzy, Porto Alegre: L\&PM, 2014. passado pela população pobre. Percebemos o desconforto do setor reacionário quanto às pautas humanitárias quando veiculam o discurso de que "defendemos bandidos", sendo que na verdade lutamos contra as raízes do problema - a desigualdade social e a desumanidade das classes dominantes.

A luta não deve consistir apenas em pressionar a legislação para que incorpore os Direitos Humanos ao "direito positivo", mas sim de mobilizar uma ação coletiva e horizontal visando garantir a proteção do indivíduo para que possa viver livremente e em igualdade com os demais membros da sociedade, amparado contra as formas de violação de sua integridade física e psicológica. As periferias devem aderir a esse movimento, como modo de defesa contra a violência que atormenta as áreas abandonadas pelo poder público.

Martins (1978) já demonstrou como diferentes pontos de vista sobre o humano podem gerar divergências acerca do que deve ser considerado direito de todos e todas. Mesmo que não citado diretamente pelo autor em consideração, vale lembrar a existência de concepções de Homem que miram a extinção dos Direitos Humanos e a anulação do outro; concepções que insistem em afirmar a própria superioridade de raça, credo, cultura ou gênero. Interessante notar que uma tese com mais de 140 anos como a de Bakunin (2011), seria capaz de anular essas concepções equívocas ao demonstrar que, em primeiro lugar, somos animais pertencentes à mesma espécie - sendo a diversidade algo natural; em segundo lugar, somos todos dotados da capacidade de pensar - todos os seres humanos possuem consciência, ideias e sentimentos; terceira e ultimamente, que almejamos pela liberdade, e que essa busca nos levará, em última instância, ao ato de revoltar-se. 


\section{REFERÊNCIAS}

BAKUNIN, Mikhail. Deus e o Estado. Tradução de Plínio Augusto Coêlho. São Paulo: Hedra, 2011.

BENJAMIN, Walter. "Teses sobre a filosofia da história.” In: KOTHE, Flávio (Org.). Walter Benjamin. São Paulo: Ática, 1985, p. 153-164.

COMPARATO, Fábio Konder. A Afirmação Histórica dos Direitos Humanos. São Paulo: Saraiva, 2012.

HOBSBAWM, Eric J. Era dos extremos: o breve século XX: 1914-1991 / Eric Hobsbawm; Tradução Marcos Santarrita. São Paulo: Companhia das Letras, 1995.

MARTINS, Waldemar Valle. "Direitos Humanos: Aspectos Filosóficos." In: Direitos Humanos. Série TEOLOGIA EM DIÁLOGO - Estudos Faculdade de Teologia Nossa Senhora da Assunção. São Paulo: Edições Paulinas. São Paulo-SP, 1978.

OTTE, Georg; VOLPE, Miriam Lídia. "Um olhar constelar sobre o pensamento de Walter Benjamin.” In: Fragmentos: Revista de Língua e Literatura Estrangeiras, v. 18, Florianópolis, SC, 2000.

Submetido em: $23-8-2018$

Aceito em: 18-12-2018 